\title{
Time Travel and the Movable Present ${ }^{1}$
}

\author{
Sara Bernstein
}

Science fiction has made time travel seem familiar and natural. Usually, time travel goes something like the following: a time traveler enters a time machine, flips a switch, and exits the time machine in, say, 1960. Then the time traveller embarks on adventures that create vexing logical and metaphysical paradoxes: killing her own grandfather, or throwing herself a $10^{\text {th }}$ birthday party that didn't occur in the first place. Philosophical literature on time travel focuses largely on paradoxes generated by time travel to the past (and more rarely to the future). But less attention is paid to what the time travel itself consists in.

This paper develops one such conception by extracting a principle from a recently proposed model of time travel, and building on it. In "Changing the Past" (2010), Peter van Inwagen argues that a time traveler can change the past without paradox in a growing block universe. After erasing the portion of past existence that generates paradox, a new, nonparadox-generating block can be "grown" after the temporal relocation of the time traveler.

This discussion articulates and expands on the underlying mechanism of Van Inwagen's model: the time traveler's control over the location of the objective present. Van Inwagen's discussion is aimed at preventing paradox by changing the past, but I argue that it provides metaphysical tools for a new model of time travel that can be generalized to all theories of time. ${ }^{2}$

Roadmap: in section 1, I lay out the requisite conceptual tools for discussing time travel. I also give a brief summary of Van Inwagen's view. In section 2, I distinguish between two different conceptions of time travel: (i) a traditional conception in which the time traveler does not move the location of the objective present, and (ii) time travel in which the time traveler shifts the location of the objective present. I then articulate and explore the latter model, which I call movable objective present, or MOP. After generalizing MOP to presentist, moving spotlight, and growing block theories of time, I present interesting possible errors of MOP travel.

\footnotetext{
${ }^{1}$ I owe thanks to audiences at the 2014 Pacific APA and the Gargnano Philosophy of Time Conference for feedback on this paper. I am also grateful to Melissa Schumacher and Heather Wallace for helpful comments. ${ }^{2}$ Hudson and Wasserman (2010) argue for a similar conclusion, but do not identify or utilize the more general mechanism of the movable objective present. They argue that hypertime is the key feature that allows the generalization of the model; here I argue that MOP is also essential to the model.
} 


\section{THEORIES OF TIME AND TIME TRAVEL}

Before delving into models of time travel, it will be helpful to discuss relevant views on the metaphysics of time. Eternalism holds that all times are equally real. There is no meaningful metaphysical distinction between the past, present, and future; Abraham Lincoln is just as real as the iPhone 47. Whether or not one is located in the present is merely a matter of perspective, akin to whether or not one is located "here" in the spatial manifold.

Presentism holds that only the present is real. Everything that exists is present; nonpresent things do not exist.

Growing block holds that the past and present are real. The growing blockist shares the eternalist's belief in the reality of the past, but stipulates that the present is the "growing edge" of being. With every passing moment, the total amount of being expands.

There are additional questions about the existence and metaphysical status of the objective present. Roughly, the existence of an "objective present" implies that a present time slice is metaphysically privileged in some way. Eternalism, presentism, and growing block vary with respect to the existence of a privileged or objective present. Eternalism denies the existence of such a privileged present, though often includes a subjective present that consists in the perspective of being present without metaphysical privilege. Moving spotlight holds that the present is privileged within the eternalist block by a kind of spotlight that "illuminates" temporally successive slices of the universe. Presentism implies the existence of an objective present by holding that what exists just is the objective present. Growing block holds that the objective present corresponds with the forward-moving bleeding edge of existence.

Whether or not there $i s$ an objective present has deep and important implications for models of time travel, and I will not give an argument for its existence here. Nor will I take a stand on which view of time is correct. I will only work with theories of time that accept an objective present: presentism, growing block, and moving spotlight theory. I will also assume that we can make sense of the idea of an objective present, and that it can ground a certain type of time travel.

Onto Van Inwagen's model. Using the growing block theory of time, Van Inwagen proposes a model of time travel according to which a time traveler relocates herself to an earlier temporal location in the existing block and annihilates the part of the block between her temporal points of departure and arrival. From the point of arrival, a new, paradox-free 
block is generated.

Let us examine this model in more detail. Consider a normal growing block universe, represented by the following diagram:

(a) Growing block universe

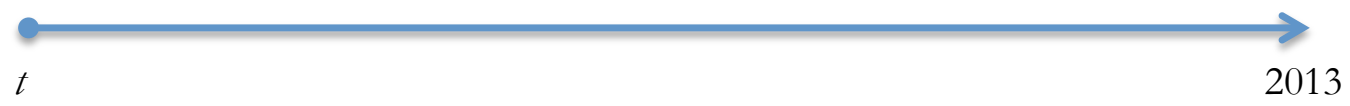

Let $t$ represent the beginning of time, and 2013 be the present. Imagine that Bianca, living in 2013, regrets not attending Woodstock in 1969. Here we have the timeline as it occurred, without Bianca having attended Woodstock:

(b) No time travel

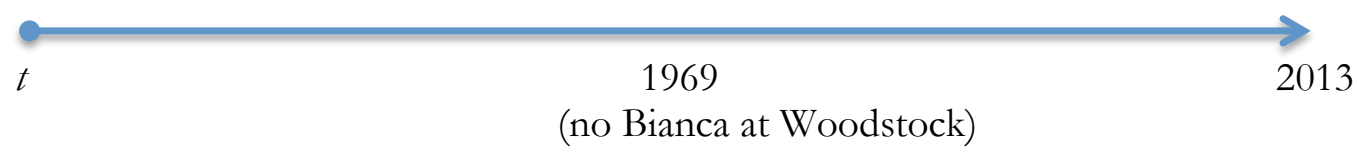

Now, according to Van Inwagen's model, a time traveller can travel to an earlier point in the block and erase the portions of the block in between the temporal points of departure and arrival. Suppose that Bianca travels from 2013 to 1969 (arriving very shortly before Woodstock so that she can attend the event). In doing so, she annihilates the portion of existence between 1969 and 2013, like so:

(c) Time travel

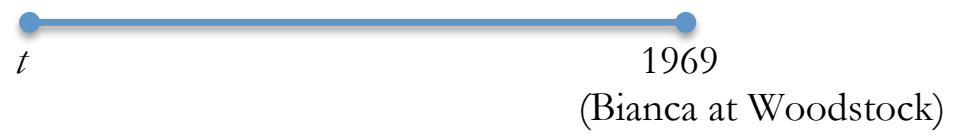

Post-time travel, Existence is 44 years smaller than it was before. Bianca attends Woodstock, which she did not do the first time around. Whereas "normal" time travel generates a paradox between Bianca's initial non-attendance and later attendance at Woodstock, Van Inwagen's scenario avoids such a problem: Bianca erases the portion of the block in which her initial nonattendance at Woodstock (plus all of the relevant after effects) occurs. After Bianca's time travel, the portion of the block beginning with her arrival is regenerated like so: 
(d) Time travel plus regeneration

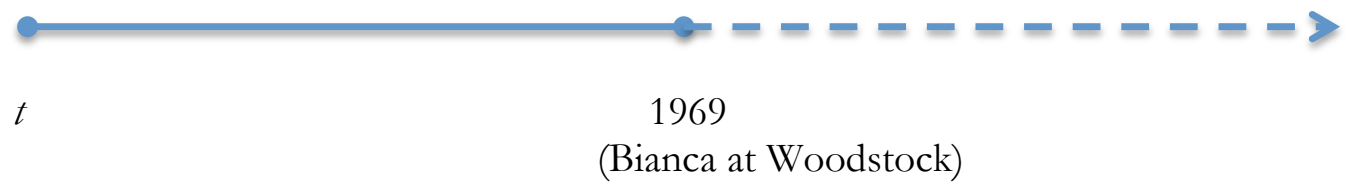

The year 1969 onward occurs a second time around. Only Bianca remembers the "first" time 1969 occurred. But others do not, for she has removed their post-1969 time slices from existence in virtue of having removed all of post-first-time 1969 from existence. And given that Bianca changes the events in second-time-around-1969 with her very presence, nothing else is guaranteed to go the way it did the first time. The end of the Vietnam War, the invention of the microchip, sequencing the human genome: they may not happen, given changes to the past and new regeneration of the block.

Van Inwagen's model makes use of bypertime. Hypertime, roughly, is a temporal manifold within which another temporal manifold exists. To make this idea clearer, van Inwagen considers an Intelligence that exists outside of time but which sees events in reality unfold in the order in which they occur in hypertime. However time is affected by time travel, the Intelligence will see the unfolding of events hyperchronologically in the passage of hypertime. For example, suppose that a time traveller "rewinds" Reality from t5 to t3. And suppose that the time traveller lives out her years happily in $t 3$, "regenerating" existence from $\mathrm{t} 3$ onwards. From within the temporal manifold, events occur in the following order: t3, t4, t5, t3, t4, t5. From the hypertemporal perspective, events occur in the following order: ht3, ht4, ht5, ht6, ht7, ht8. Events whose temporal orders are shifted in time nonetheless have a linear progression in hypertime.

Without time travel, time and hypertime agree on the order of events. According to van Inwagian time travel, time and hypertime disagree on the order of events. Consequently, events can also have different temporal and hypertemporal tenses: the van Inwagian time traveler can attend an event that is in the past and in the hyperfuture, such as Woodstock.

Similarly, van Inwagian time travel results in a durational discrepancy between time and hypertime. Suppose that hypertime is finite and that it lasts for 1000 temporal units. Normally, the quantity of existence of the growing block universe grows steadily in such a way that time and hypertime agree on its duration: when existence is 400 temporal units long, hyperexistence is also 400 temporal units long. But time travel in which a portion of the growing block is erased generates hypertemporal duration that exceeds temporal 
duration. Consider our time traveller's erasure of the span of existence between 1969-2013. The duration of time extends to 1969, but hypertime marches on past hyper 2013 —44 more hyperyears than the temporal manifold (assuming that is the only erasure).

\section{THE TRADITIONAL MODEL VERSUS MOVABLE OBJECTIVE PRESENT}

2.1 The Traditional Model: Relocation. Suppose that Bianca travels to 1969 from 2013. According to the traditional model of time travel, she removes herself from the present day and relocates herself to 1969, leaving the extant temporal manifold intact. The traditional model conceptualizes travel through time as similar to everyday travel through space: just as one does not change the fundamental nature of space by changing spatial locations, one does not change the fundamental nature of time by changing temporal locations. ${ }^{3}$ One space travels by moving through space, but not by changing space itself. On the traditional model of time travel, one travels through time by moving through time either backwards or forwards, but does not change the fundamental temporal manifold by doing so.

For example, when Bianca leaves 2013 for 1969, she leaves one temporal part of the universe behind (2013), according to the traditional model, and arrives in another temporal part of the universe (1969). ${ }^{4}$ Like travel through space, the mechanism of traditional time travel is simple relocation in which the time traveller removes herself from one part of the temporal manifold and places herself at another. Just as one does not destroy or affect the rest of the spatial manifold by driving to a coffee shop, one does not destroy or affect the temporal manifold by moving from one location to another.

Importantly, Bianca also leaves others "on the ground" while she travels. Barring well-known paradoxes involving parent and grandparent-killing, she does not change her mother's existence in 2013 merely by travelling through time. Rather, Bianca leaves her mother "behind" in 2013 as she relocates herself to 1969, much as I leave my home behind when I head for work. This feature reflects the traditional conceptualization of time travel as a kind of relocation of the time traveller similar to spatial relocation.

According to Lewis (1976), time travel also involves a disagreement between personal time and external time. Personal time, roughly speaking, is the time on the time

\footnotetext{
3 One might change the size and shape of spacetime by time travelling in this way, but not the fundamental nature of time itself.

${ }^{4}$ Here I set aside well-known issues involving "second time around" time travel, i.e., the idea that the time traveler must have always been in 1969.
} 
traveler's watch. External time is the time elapsed on the basic timeline. Suppose that travel from 2013 to 1969 takes Bianca exactly one year. One year of personal time has elapsed for Bianca for the 53 external years she has travelled. Accounts differ on whether personal time is "real" time, but the idea is that traditional time travel involves timelines split between the time traveller and the external timeline. Similarly, the van Inwagian model involves a disagreement in the durations of time and hypertime: the time traveler relocates the edge of time, while hypertime lurches forward.

2.2 The New Model: Movable Objective Present (MOP). I propose that the distinctive feature of van Inwagen's model is the time traveler's control over the location of the objective present. When the time traveler flips the switch in the time machine, she does not simply relocate berself to a different spot in the temporal manifold, as on the traditional model. Rather, she changes the location of the objective present for the entire temporal manifold: she shifts the location of the objective present to the past of the temporal manifold, as hypertime marches on. I call this sort of time travel movable objective present (hereafter: MOP). MOP is unique because the mechanism of time travel involves a change in the location of the objective present in addition to relocation of the time traveller. ${ }^{5}$

Before exploring MOP in further detail, it will be helpful to separate the key features of MOP from Van Inwagen's model. The latter proposes that the time traveller annihilate the time slices between 1969 and her initial moment of travel in 2013. But annihilation is not essential to MOP: MOP only necessitates the time traveller's control over the location of the objective present. A time travel machine might also generate time slices into existence, as in time travel to the future. ${ }^{6}$ The movement of the objective present doesn't necessitate a change in the duration of Reality. Nor does MOP require the acceptance of the growing block theory of time. The presentist MOP traveller travels in time by relocating the exclusive slice of existence to her desired temporal destination in hypertime. The moving spotlight MOP time traveller travels by relocating the spotlight of the present to her desired destination in the eternalist block. I will explore these different conceptions later in further detail, but for now the important points are that MOP requires neither annihilation of existing time slices nor the growing block theory of time.

\footnotetext{
5 Technically, the location of the present need not be under the control of the time traveller herself. For example, there could be a "jumpy" objective present that spontaneously switches locations in hypertime, and is not under a time traveller's control. Here I set aside such cases.

${ }^{6}$ Hudson and Wasserman (2010) suggest this as well.
} 
MOP requires the existence of an objective present. Presentism, moving spotlight, and growing block agree on its existence, but disagree on its nature. I do not take a stand on this important issue here, but I do make a few assumptions. First, I assume that the objective present is causally receptive: those existing within it are able to push, pull, move, and change features of reality. The present reality is dynamic and changeable. Whatever distinguishes the objective present from other temporal locations, one of its distinctive features is its receptivity to modification and change. ${ }^{7}$ Looking down at the temporal manifold, the Intelligence thus sees at least one temporal part of Reality glimmering with change and activity. Second, I assume that the objective present is maximally temporally thin: it is the smallest unit of time rather than, e.g., a year-long temporal part of the block.

MOP requires the time traveller's ability to "grasp" and control the location of the objective present. Admittedly, the mechanism of such "grasping" is unclear: MOP compounds the conceptual and metaphysical oddness of time travel by requiring that the traveller have a handle on the entire present, not just on her own temporal location. The MOP traveller's machine is thus more powerful than the traditional time travel machine: it must control the objective present in addition to the temporal location of the time traveller.

MOP time travel has two key features: movability of the objective present, and relocation of the time traveler. MOP requires that the time traveller be able "grasp" the present, so to speak, and then shift it to her desired location in the temporal manifold. Grasping onto and relocating the objective present differs from the traditional model in that the traveler shifts time around her rather than solely shifting her location in time. According to the traditional model, the occurrence of time travel doesn't necessitate a wholesale change for the rest of reality. On MOP, the very mechanism of time travel is a fundamental change in the location of the objective present.

MOP must include relocation of the time traveller in addition to the shift of the objective present. Merely "rewinding" the block doesn't guarantee that the time traveler is relocated, since the block rewinds to a location that might predate the existence of the time traveler and the time machine without her inclusion. Moreover, if the time traveler shifts the objective present without including herself, the result is that reality "resets" to the prescribed location in the temporal manifold and reality proceeds as it would have absent the time traveler and her machine. Given determinism, it is the inclusion of the time traveler that

\footnotetext{
${ }^{7}$ Whoever is in the objective present, can change it. A time traveller can change the past, according to MOP, because she can relocate the objective present in order to render it susceptible to change.
} 
regenerates reality differently.

Let's look at an example. Suppose that a MOP traveller who lives in 2013 sets her time machine to return to 1969. She must flip two switches: first, the switch that relocates the objective present from 2013 to 1969; second, the switch that preserves the time traveler and her machine as the present is relocated. Why the latter? Because relocating the objective present to 1969 only guarantees that the universe is "reset" to that time-a time that might predate the existence of the time traveller and her time machine. For MOP to count as time travel rather mere resetting, it must involve inclusion of the time traveler.

Supposing that both switches have been flipped, the traveller moves herself and the objective present to 1969. The MOP time traveler is selfish: she moves the location of the objective present for everyone, rendering many of the other inhabitants of 2013 inert or non-existent. If time travel takes time, MOP entails that the traveler's personal time en route adds to the hypertemporal duration of the MOP traveller's trip. Suppose that the MOP machine takes one year to do its work, and that the time traveller leaves 2013 for 1969. Upon time traveller's arrival, the hyperpresent will be located in hyper 2014, even as the present is (re)located in 1969.

Three questions: What are the time traveller's abilities in the relocated objective present? What happens to the rest of the temporal manifold after MOP occurs? And what does the Intelligence see? Answers to all three questions depend on the theory of time in question. I now turn my attention to more specific models of MOP: presentist MOP, moving spotlight MOP, and growing block MOP.

2.3 Presentist MOP. It is generally thought that time travel is incompatible with presentism, for the reason that no destination exists to which the time traveler can depart. ${ }^{8}$ At best, she has no destination to which to travel; at worst, the time traveler effectively kills herself by flipping the switch in the time machine. This is commonly known as the "No Destinations" problem for time travel in a presentist universe.

MOP defies this dogma. For the presentist who accepts hypertime, MOP consists in the time traveller's relocation of the unique slice of existence to a different point in time. Suppose that the time traveller hops into the time machine in 2013 and sets her destination to 1969 . According to presentist MOP, the time traveller "rewinds" the objective present to

\footnotetext{
${ }^{8}$ See Hales (2010).

9 See Gray (1999) for one prominent version for this argument.
} 
1969, allowing her to change events as she sees fit. As on van Inwagen's model, (i) only the time traveller's memories postdate 1969, (ii) Reality progresses from the time traveller's arrival. The presentist MOP traveller can change past occurrences as she chooses without creating a paradox. Suppose that, remembering her sadness over failing to attend Woodstock, she travels back to 1969 to attend. Future events with which the "initial" Woodstock would conflict, such as the consequent sadness, do not exist; Bianca "resets" reality at 1969 , allowing it to progress according to the causal results of her attendance at Woodstock.

The Intelligence sees individual slices of existence successively pop into existence in hypertime. Temporal locations are repeated, but hypertemporal locations are hyperchronological. The Intelligence views events in hyperchronological order. Suppose that Woodstock occurs in 1969 (t1); that Bianca's sadness over not attending Woodstock begins in 1970 (t2); that her eventual time travel occurs in 2013 (t3); that she attends Woodstock after MOP travel to 1969 (t1); and that she is happy in second-time-around 1970 as a result (t2). The Intelligence views these events in the following hyperchronological order: $\mathrm{t} 1 / \mathrm{ht} 1$, t2/ht2, t3/ht3, t1/ht4, t2/ht5.

Since presentist MOP "resets" the objective present, its effect on the extant temporal manifold bears similarity to van Inwagian time travel with annihilation: the result of the time traveller's voyage is the removal of the extant times from existence, leaving events to regenerate differently the second time around. For example, suppose that post-MOP Bianca cleverly picks up a lottery ticket 1970, already aware of the winning numbers from her careful study of lottery history in 2013. Winning the lottery generates no paradox, since there are no existent events (Bianca's financial concern in 1972, for example) with which the event would conflict.

2.4 Growing Block MOP. In a growing block universe, the MOP traveler sets her time machine to her desired destination and moves herself and the objective present to a different temporal location. Growing block MOP differs from van Inwagen's view in that slices of existence are not necessarily annihilated: the objective present is relocated, but the quantity of temporal existence remains intact.

What happens to the growing edge of being when the present disagrees with the hyperpresent? Here are several options. First option: Being stops its growth the moment the time traveller leaves, with hypertime marching forward past the bleeding edge of Being. 
Second option: Being is insensitive to time, such that a changeless, dark portion of reality continues to grow in step with hypertime past the moment of the traveller's departure. Third option: contra MOP, the block is annihilated by the time traveller's relocation by necessity. Which option obtains depends on the relationships between the objective present, the hyperpresent, and the growing edge of being. If the growing edge of being just is the objective present, then van Inwagen's picture (the third) is correct by metaphysical necessity. If hypertemporal location directly following the objective present is only necessary for change, then option two is correct: a changeless, dark Reality continues to grow in step with hypertime, unilluminated by the possibility of change conferred by the objective present. Finally, if the objective present is what brings Reality into existence, then the first option obtains: moving the objective present behind the bleeding edge of being halts the movement and generation of Reality.

What are the time traveller's abilities, given the existence of the past? A critical assumption of MOP is that the objective present confers casual receptivity: what exists within the objective present is changeable and dynamic. Suppose that Bianca moves herself and the objective present from 2013 to 1969, causing hypertime to creep past the bleeding edge of Being. And suppose that previously, 1969 included neither her arrival via time machine nor her attendance at Woodstock. But if the objective present is causally receptive, Bianca can attend Woodstock the second time around. How can this occur given the existence of the past?

Growing block MOP requires that the time traveler regenerate a new block of Reality that "saves over" the existing temporal manifold. Given the acceptance of hypertime, the idea is that there is a new block at every hypermoment, and that there can be replacement blocks at successive hypermoments. Each new replacement block determines all the facts about the past and the present. In giving a characterization of changing the past in an eternalist universe, Hudson and Wasserman state this idea well:

"Suppose that at ticktock 100 an eternalist block is hyperpresent and determines all the facts about the past and the future (relative to each of its time-slices). Further suppose that at ticktock 101, with the sole exception of some slice, S, a new eternalist block has replaced the old one [...] The items that characterize the eternalist block at ticktock 101 determine all the facts about the past and the future 
(relative to each of its time-slices, as well) [...]."10

The key feature of the model is that the block generated by the time traveler hyperfollows the existing block in which the past is fixed. In the eternalist model, the new block fixes all facts about the past, present, and future. This feature can be adapted to growing block by holding that each new block determines the facts about the past and present, until the hypernext block is generated.

Here's how it works. Call Bianca's failure to attend Woodstock state W-, and Bianca's attendance at Woodstock state $\mathrm{W}+$. The Intelligence sees the block in state $\mathrm{W}$ - at hypertime 1, Bianca's time travel at hypertime 2, and state $\mathrm{W}+$ at hypertime 3 . At hypertime 2 , a new block is generated in place of the old one. The Intelligence sees the appearance of a new block hyperafter the existence of the hyperolder block that contains state W-: at hypertime 2, all of Reality is replaced by a new, maximally determinant block. As Hudson and Wasserman put it:

“... At] ticktock 99, it was true both that you did not have the fabulous past you'd been dreaming about and you will not have the glorious future you'd been hoping for, for at ticktock 99, it is true that the machine will not work. [But] at ticktock 101, it was true both that you did have the fabulous past you'd been dreaming about and you will have the glorious future you'd been hoping for, for at ticktock $101[\ldots]$ the machine did work."

In other words: the block determines all of the past and present facts, but a different hypersuccessive "replacement" block determines all of the past and present facts at the next hypertemporal moment.

Above, I discussed how MOP compounds the conceptual oddity of time travel by requiring that the time traveler's machine have control over her temporal relocation and over the location of the objective present itself. For growing block MOP, the time traveller's machine must also have powers of block regeneration: broad powers indeed, but not necessarily a further stretch beyond traditional time travel. What MOP loses in requirements on the abilities of the time traveler and time machine, it gains in rejection of well-known

${ }^{10}$ Hudson and Wasserman (2010: 6). 
paradoxes about changing a fixed past.

2.5 Moving Spotlight MOP. Moving spotlight MOP consists in the time traveller's control over and movement of the "spotlight" to her desired temporal location. According to moving spotlight MOP, the mechanism of time travel is the illumination or reillumination of a location in the block. MOP causes a disruption in the successive temporal order of the objective present.

To illustrate, let us return to Bianca, who desires to use her time machine in 2013 in order to attend Woodstock in 1969. Suppose, as before, that Woodstock occurs in 1969 (t1); that Bianca's sadness over not attending Woodstock begins in 1970 (t2); that her eventual time travel occurs in 2013 (t3); that she attends Woodstock after MOP travel to 1969 (t1); and that she is happy in second-time-around 1970 as a result (t2).

Without time travel, the location of the objective present is successively ordered. For example, it is located at $\mathrm{t} 1$, at $\mathrm{t} 2$, at $\mathrm{t} 3$, and then at $\mathrm{t} 4$. With time travel, temporal locations of the objective present are repeated: the objective present is located at 1969 several times over. The Intelligence views the location of the objective present in the following hyperchronological order: $\mathrm{t} 1 / \mathrm{ht} 1, \mathrm{t} 2 / \mathrm{ht} 2, \mathrm{t} 3 / \mathrm{ht} 3, \mathrm{t} 1 / \mathrm{ht} 4, \mathrm{t} 2 / \mathrm{ht} 5$. As Bianca arrives in 1969, the Intelligence sees the objective present "jump" backwards in the block.

As on the growing block model, moving spotlight MOP requires that the hyperpresent block regenerate and replace the old block in hypertemporal succession. At $\mathrm{t}$, Bianca relocates the illuminating spotlight of the present to 1969. Upon her arrival, a new hyperpresent block is generated that contains both her arrival and her attendance at Woodstock: the shared slice between the hyperearlier block and the block that replaces it. ${ }^{11}$ At each hypermoment, a spotlight illuminates a portion of the block. With the addition of time travel, the block is replaced by a new block and, presumably, a new spotlight: the spotlight shone on the time traveller.

\section{MOP ERRORS AND EXTANT QUESTIONS}

The possible errors of the MOP mechanism are many. First, we can imagine the all-

\footnotetext{
11 Since the goal is to apply MOP to various theories of time, I assume with Hudson and Wasserman that we can make sense of multiple hyperpresent blocks. Elsewhere (Bernstein MS), I explore the coherence of this idea and suggest that it can be fleshed out using hyperhypertime.
} 
important first switch making a mistake and taking too little or too much of present reality with it. Suppose that Bianca jumps into her time machine in 2013 and flips both switches. But unbeknownst to her, the temporal relocation switch malfunctions: rather than transport Bianca and her time machine to 1969, it transports only the time machine. Bianca is out of luck: the objective present has been relocated without her and her time machine is missing. More seriously, if her malfunction occurs in a presentist universe, she has taken her Woodstock-desiring self out of existence, since the objective present is relocated to the past without her. If the malfunction occurs in a growing block or a moving spotlight universe, then the slice of Reality shared by the hyperolder block and the hypernew block shares the time machine but lacks Bianca. Either way, the past has been changed, but only by the presence of the time machine: Bianca has lost her chance.

Or suppose that the temporal relocation switch malfunctions in the other direction, and brings, along with the time machine, the maximal spatial slice of January 7, 2013. That is, suppose that the malfunctioning relocation switch essentially duplicates the state of the universe on January 7, 2013 in 1969: the Vietnam War has ended, the microchip has been invented, and the human genome has been fully sequenced. If this occurs, then 2013-in-1969 progresses largely as hyper-2013 would have progressed, save for the addition of the time traveller and her machine. Suppose that Bianca sets her faulty time machine to 1969 in 2013 (t3), transports the spatially maximal time slice of January 7, 2013 to 1969 (t2), and lives out the confusing reality in 1969 (t1). The Intelligence views the unfortunate scenario in the following way: 1969 occurs the first time around; Bianca spatially transports the maximal slice of January 7, 2013 to 1969; the world evolves largely as it was going to if the time travel didn't happen.

Another possible serious MOP error is the existence of competing time travellers whose desired locations for the objective present conflict with each other. This is a special problem for MOP, since the mechanism of time travel relies on the relocation of the unique objective present rather than the relocation of the traveler alone. Here is how such a scenario would go. Suppose that in addition to Bianca, there is a second time traveler, David, in possession of a relocation-and-objective-present movement device. On January 7, 2013, Bianca sets her device for 1969 and David sets his device for 1950. One reading of the results involves multiple compossible objective presents: multiple causally receptive time slices within which the time travellers can generate change. Given the possibility of logically incompatible changes incurred by each time traveler, I leave it as an extant question whether 
such a scenario is metaphysically possible.

MOP raises additional extant questions about the relationships between the objective present, the passage of time, existence, and hypertime. The conceptual possibilities of MOP show that these features hang together and come apart in interesting and intricate ways. To what extent does the passage of time determine the location of the objective present? Does the objective present bring Reality into being, or simply march in step to its generation? MOP doesn't answer these questions, but modeling it within different theories of time shows that the possibilities are more subtle than previously imagined.

\section{CONCLUSION}

The underlying mechanism behind van Inwagen's model is the movable objective present. The idea is that the objective present is under the control of the time traveller and that she can move it anywhere in the temporal manifold. In contrast to the traditional model that conceptualizes time travel as a type of temporal relocation, MOP involves the time traveller's movement of the entire objective present in addition to her temporal relocation. Given the acceptance of hypertime, MOP is generalizable to presentist, growing block, and moving spotlight theories of time. While MOP is slightly different for each, it allows the metaphysician to believe in the possibility of time travel without assuming a particular theory of time.

MOP also reveals the intricate relationships between the objective present, the passage of time, existence, and hypertime. While time travel is normally considered an outré test case for theories of time, MOP reveals that time travel can be utilized as a novel conceptual tool for modeling these relationships in further detail. 


\section{REFERENCES}

Bernstein, S. (MS), 'Hudson and Wasserman on Time Travel'.

Grey, W. (1999), 'Troubles with Time Travel, in Philosophy 74, 55-70.

Hales, S. (2010), 'No Time Travel for Presentists', in Logos and Episteme (2):353-360.

Hudson, H. and Wasserman, R. (2010), 'Van Inwagen on Time Travel and Changing the Past', in D. Zimmerman (ed.), Oxford Studies in Metaphysics, v.5 (Oxford University Press).

Lewis, D. (1976), 'The Paradoxes of Time Travel', in American Philosophical Quarterly 13 (2):145-152.

Sider, T. (2005), 'Travelling in A and B Time', in The Monist 88 (3):329-335.

Van Inwagen, P. (2010), 'Changing the Past', in D. Zimmerman (ed.), Oxford Studies in Metaphysics, v.5 (Oxford). 